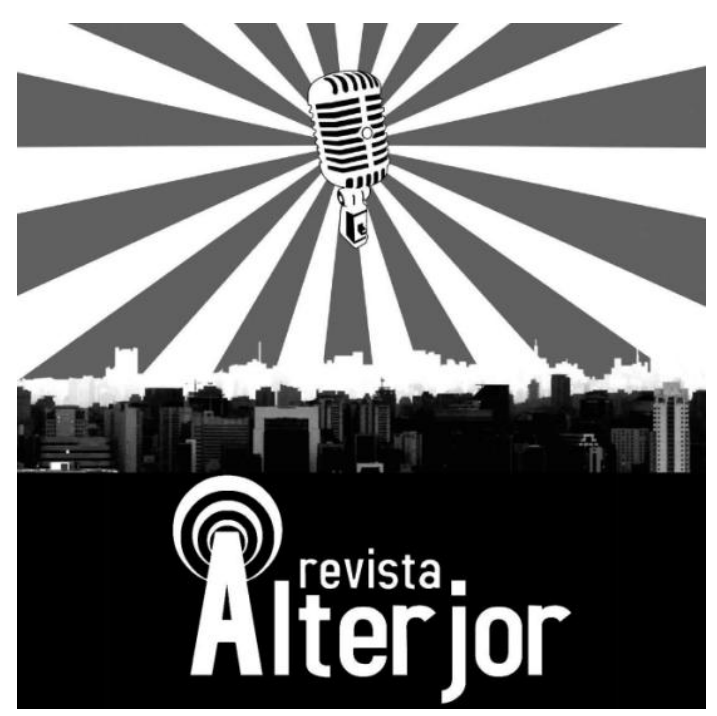

\title{
A PROPAGAÇÃO DE DESINFORMAÇÃO EM TEMPOS DE CORONAVÍRUS: CONSIDERAÇÕES EM TORNO DO PROGRAMA "FATO OU FAKE"
}

\author{
Juliana Lopes de Almeida Souza ${ }^{1}$ \\ Leandro de Resende ${ }^{2}$
}

RESUMO: O presente estudo tem como objetivo explorar o conceito de notícia e de desinformação, a fim de evidenciar os prejuízos que conteúdos falsos ou fora de contexto podem trazer para a sociedade. Foi desenvolvida uma pesquisa de caráter descritivo. Utilizou-se para a investigação considerações em torno de um estudo de caso, analisando o papel do programa "Fato ou Fake", do G1, pelas fases de criação, produção e distribuição de informações. Destaca-se que o programa combate as desinformações relacionadas ao coronavírus no Brasil, caracterizado por três elementos: agente, mensagem e intérprete. O artigo propõe que a desinformação pode causar interferências, inclusive, na saúde e bem-estar da população. Por causa disso, é necessário combater conteúdos falsos e descontextualizados, tendo em vista a responsabilidade dos canais de comunicação, mas também dos indivíduos que compartilham as informações sem verificação das fontes.

PALAVRAS-CHAVE: Desinformação. Fake News. Notícia. Fato ou Fake. Coronavírus.

ABSTRACT: The search aims to explore the concept of news and misinformation, in order to highlight the damage that false or out of context content can bring to society. Considerations around a case study were used for the investigation, analyzing the role of the G1 "Fato ou Fake" program, by the phases of creation, production and distribution of information. It is noteworthy that the program combats misinformation related to the coronavirus in Brazil, characterized by three elements: agent, message and interpreter. The article proposes that misinformation can cause interference, including, in the health and well-being of the population. Because of this, it is necessary to combat false and decontextualized content, in view of the responsibility of the communication channels, but also of the individuals who share the information without checking the sources.

KEYWORDS: Disinformation. Fake News. News. Fato ou Fake. Coronavirus.

\footnotetext{
' Professora nos cursos de Graduação e Pós-graduação da UNA e UNIBH. Doutoranda em Comunicação Social pela Universidade Federal de Minas Gerais - UFMG. Mestre em Ciência da Informação pela UFMG. Graduada em Comunicação Social pelo UNIBH, E-mail: julianasouza@prof.una.br.

${ }^{2}$ Pós-graduado em Marketing Estratégico pela Pontifícia Universidade Católica de Minas Gerais - PUCMinas. Graduado em Comunicação Social com Ênfase em Publicidade e Propaganda pelo Centro Universitário Una. E-mail: leandroderesende@ hotmail.com
}

Revista ALTERJOR

Grupo de Estudos Alterjor: Jornalismo Popular e Alternativo (ECA-USP)

Ano 10 Volume ol Edição 23 Janeiro-Julho de 2021

Avenida Professor Lúcio Martins Rodrig̉ues, 443, Cidade Universitária, São Paulo, CEP: 05508-020 


\section{Introdução}

Notícias falsas ou descontextualizadas circulam livremente nos canais de comunicação. Em constante preocupação, as notícias jornalísticas precisam ser verificadas diante das fontes de informação. Na Era Digital, a noticiabilidade verídica continua sendo necessária. Marinho, Marinho, Marinho (2011, p.1) apresentam o conceito Era Digital como o período "em que o indivíduo isolado tem facilmente acesso a uma audiência potencialmente ampla para divulgar o que quer que seja", destacando a livre expressão como um de seus benefícios. Entretanto, ela se torna prejudicial a partir do momento em que é utilizada para compartilhar informações duvidosas. Em canais em que todos usuários podem ser produtores de conteúdo e influenciadores, as notícias falsas ganham o potencial de se tornarem objetos prejudiciais à sociedade, influenciando pensamentos e comportamentos.

A pandemia do coronavírus direcionou os olhares da população para os informativos, expondo diferentes comunidades à diversidade de informações relacionadas ao tema. Da mesma forma, notícias falsas e fora de contexto surgiram em grande proporção, influenciando comportamentos capazes de impactar, inclusive, a saúde e o bem-estar social.

Jenking, Green, Ford (2014) comentam que, ao compartilhar um conteúdo, as pessoas avaliam se ele é valioso para os grupos em que há interação constante. Esses conteúdos têm ativadores culturais que oferecem atividades das quais esses interlocutores podem participar. Para os autores, "esse conteúdo muitas vezes é propagado quando as pessoas são compelidas a falar, conscientemente ou não, o que pensam, mas lhes falta uma linguagem para se comunicarem" (JENKINS, GREEN, FORD, 2014, p.279). O indivíduo que contribui com a propagação de uma mensagem falsa ou descontextualizada não tem, necessariamente, o objetivo de prejudicar demais interlocutores da mensagem.

Ao analisar as desinformações relacionadas ao coronavírus, conseguimos entender os prejuízos que a sociedade pode encontrar no mundo real, fora do ambiente on-line, em que ocorre a circulação da mensagem. Por isso, as influências que as 
desinformações geram no pensamento e comportamento das pessoas são capazes de refletir, inclusive, na saúde humana.

Este estudo tem como proposta explorar o conceito de desinformação e exemplificar os prejuízos que elas podem gerar. Nesse sentido, a pergunta que norteia este estudo é: como as desinformações relacionadas ao coronavírus estão sendo combatidas e de quem é a responsabilidade para combatê-las?

O estudo visa analisar as desinformações relacionadas ao coronavírus no Brasil a fim de entender como elas estão sendo esclarecidas à população. Os objetivos específicos visam entender o conceito de notícia e desinformação, bem como analisar a atuação do programa "Fato ou Fake", do G1, no combate às informações falsas e descontextualizadas. A seguir, apresenta-se a contextualização adotada com a finalidade de explorar os principais pontos de partida deste estudo: o conceito de notícia, de desinformação e os fatores que influenciam na propagação da desinformação, transformando-a em um objeto de investigação cíclico. Frisa-se que não há o escopo de limitar o objeto estudo, mas sim contribuir na discussão e na busca por mais dados para pesquisas futuras.

\section{Notícias falsas: a busca por um fato verdadeiro}

Alsina (2005) afirma que não é fácil definir conclusivamente o conceito de notícias e não há uma definição universal sobre isso, mas é seguro afirmar que a notícia é o produto de uma sociedade específica. Ao se questionar sobre o significado de "um fato verdadeiro" (ALSINA, 2005, p.144), explica-se que a notícia é a narração de um acontecimento em âmbito individual ou coletivo, de algo verdadeiro ou falso, com ou sem provas. Sendo assim, notícias não se tratam, necessariamente, de um fato verídico, e é mais apropriado classificá-las como a narração de um fato.

Transformar um fato em notícia é basicamente uma operação linguística, que permite uma sequência de sinais verbais (orais ou escritos) e não verbais. Essa é a tarefa específica de alguns homens e mulheres que atuam como operadores semânticos: os jornalistas (ALSINA, 2005, p.145). 
Na perspectiva pragmática do autor, a credibilidade da notícia se relaciona à ética, uma vez que a noção de verdade não está implícita no conceito de notícia, já que a verdade é uma questão de fé ou ideologia, sendo que "a veracidade da notícia é um tema absolutamente questionável” (ALSINA, 2005, p.144). As definições de notícia podem ser resumidas em dois grandes grupos: no primeiro grupo, encontra-se o conceito de notícia como um espelho da realidade; enquanto no segundo grupo, pode-se ver a notícia como uma ferramenta de construção da realidade.

Na concepção da notícia como espelho da realidade, a sociedade tem o papel de contribuir no aumento da conscientização. Nessa ótica, a notícia é apresentada como algo já feito. Enquanto no viés da concepção da notícia como construção da realidade, os membros da comunidade constroem e constituem os fenômenos sociais de forma coletiva. Apesar de as notícias não refletirem a sociedade, elas ajudam a constituí-la, uma vez que o processo de descrição do evento é o que define e molda aquele evento, constituindo um fenômeno social compartilhado.

Ainda em busca da conceituação de notícia, o autor propõe que "notícia é uma representação social da realidade cotidiana produzida institucionalmente que se manifesta na construção de um mundo possível" (ALSINA, 2005, p. 147). O termo "representação social" trata-se de um instrumento que desempenha um importante papel na comunicação e no comportamento da sociedade, com o qual o grupo ou o indivíduo compreende o seu ambiente, enquanto o "mundo possível" se trata da construção de um discurso jornalístico.

Ao entender que o discurso jornalístico se constitui pela ordem da linguagem mediante um fato, Wardle e Derakhshan (2017) contextualizam que informações fabricadas sem precedentes fazem parte do mundo moderno, que vive cada vez mais polarizado. Canais midiáticos constroem notícias enganosas pelo seu único valor de choque, o que polui as informações no mundo digital e cria desafios sem precedentes. Há uma necessidade imediata de encontrar soluções sustentáveis para o fluxo de informações poluídas, uma vez que elas contaminam o discurso público sobre diferentes questões, como na área da saúde, em que informações incorretas representam uma 


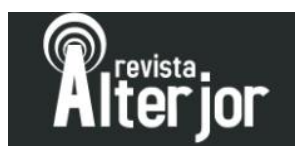

ameaça à população. Ainda que o ato da disseminação de notícias falsas não seja algo novo, a Internet e as redes sociais online trouxeram mudanças na forma de construção e distribuição da informação. A partir da sua ascensão, a construção e distribuição de conteúdo tornou-se algo acessível, barato e público.

As informações também são divulgadas em maior velocidade e passadas em tempo real entre pares confiáveis que banalizam a contestação da notícia. As redes sociais online são responsáveis por guiar a construção do conhecimento das pessoas e elas dificultam o julgamento da credibilidade das informações, fazendo com que portais confiáveis sejam facilmente confundidos com canais conspirativos. Sendo assim, as pessoas dependem cada vez mais de seus amigos e familiares para guiá-las na busca por informações e faz com que a história contada seja mais importante que a fonte. Nesta perspectiva de busca por informações, os autores explicam que há tendência por compartilhar notícias que predominam no ciclo social. Tal compartilhamento é identificado pela exposição de notícias falsas. $\mathrm{O}$ ato de compartilhar é intuitivo quando o indivíduo nota que o conteúdo é permeado por questões de crenças, sobretudo quando se constituem por conteúdo emocional.

As redes sociais são impulsionadas pelo compartilhamento de conteúdo emocional. A arquitetura desses sites é projetada de tal maneira que toda vez que um usuário publica conteúdo - e é apreciado, comentado ou compartilhado mais — seu cérebro libera uma pequena quantidade de dopamina (WARDLE $\mathrm{E}$ DERAKHSHAN, 2017, p.13).

A percepção do indivíduo de que o compartilhamento propaga informações falsas é velada, na medida em que o conteúdo pode ser percebido como verídico. Neste sentido, não há intenção, mas a forma como se propaga a desinformação deve ser investigada. Wardle e Derakhshan (2017) preferem adotar o termo "desinformação" para descrever o fenômeno de poluição ou desordem da informação, uma vez que o termo "fake news" é vago e ambíguo, tornando-o inadequado para descrever fenômenos de informações erradas e desinformações. Além disso, o termo "fake news" também começou a ser adotado por políticos para descrever notícias que lhes desagradam, o que banalizou ainda mais o seu uso. Segundo Wardle e Derakhshan (2017, p. 17) descrevem 


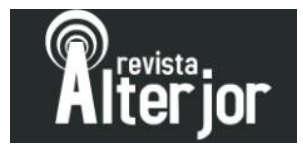

sete diferentes tipos de informações erradas e desinformações "revelando o amplo espectro de conteúdo problemático online, desde a sátira e paródia (que, embora seja uma forma de arte, pode se tornar uma informação errada quando o público interpreta mal a mensagem) até conteúdo totalmente fabricado", são eles: falsa conexão (legendas que não correspondem ao conteúdo); falso contexto; manipulação do contexto; sátira ou paródia (sem intencionalidade explícita); conteúdo enganoso (uso equivocado de dados); conteúdo impostor (uso de fontes falsas) e conteúdo fabricado (com intenção de manipular a opinião pública e prejudicar).

\section{Criação, Produção e Distribuição: fases da propagação da desinformação}

Wardle e Derakhshan (2017, p22) dividem um distúrbio de informação em três fases: "Criação: a mensagem é criada; Produção: a mensagem é transformada em um produto de mídia; Distribuição: a mensagem é distribuída ou tornada pública”. Dentro de cada distúrbio existem três elementos: o agente, a mensagem e o intérprete. Os agentes estão envolvidos nas três fases e podem ter diferentes motivações. Esses agentes podem ser oficiais, como partidos políticos e grupos de notícias, ou podem não serem oficiais, como um grupo de pessoas evangelizadas com o assunto. Os agentes podem ou não terem o intuito de enganar e prejudicar o público a fim de causar danos. Além disso, existem quatro fatores motivacionais que potencializam a criação de desinformações: financeiro, em que o agente tem o intuito de lucrar com a desordem da informação; político, na tentativa de influenciar uma opinião pública; social, para conectar-se com determinado grupo; ou psicológico, em busca de prestígio.

O segundo elemento é a mensagem, que é construída com o intuito de influenciar o público. Ela pode ser veiculada em diferentes canais, on-line e off-line, e sua durabilidade também varia de acordo com o intuito, sendo projetadas para permanecerem relevantes, de acordo com a durabilidade do evento. O intérprete, que é o terceiro elemento, é o público que recebe informações passivamente e interpreta de forma individual, de acordo com suas experiências pessoais. Para Wardle e Derakhshan (2017), a ação que o intérprete toma com a mensagem pode tornar a 
desinformação cíclica, uma vez que o intérprete assume papel de agente na distribuição do conteúdo.

O que o "intérprete" pode fazer com uma mensagem destaca como os três elementos da desordem de informação devem ser considerados partes de um potencial ciclo sem fim. Em uma era de mídia social, onde todos são editores em potencial, o intérprete pode se tornar o próximo "agente", decidindo como compartilhar e enquadrar a mensagem em suas próprias redes. Eles mostrarão apoio à mensagem, gostando ou comentando, ou decidirão compartilhar a mensagem? Se compartilharem a mensagem, farão com a mesma intenção do agente original ou a compartilharão para, por exemplo, mostrar sua discordância? (WARDLE E DERAKHSHAN, 2017, p.28)

Identificamos potencial maneira argumentativa pelo agente, mensagem e intérprete, sobretudo quando os três estão envolvidos com o ato de compartilhar a informação falsa. Para Jenkins, Green, Ford (2014, p.279) "as pessoas querem compartilhar os textos de mídia que se tornam um recurso significativo em suas conversas contínuas ou que ofereçam a elas alguma nova fonte de prazer e interesse". Os autores explicam que, para que um conteúdo seja compartilhado em massa em redes sociais online, ele só precisa ser relevante ao usuário e seus respectivos seguidores, além de ter um potencial de envolvimento de crença, sem ter, necessariamente, uma conferência da veracidade da informação - o que explica o compartilhamento de fake news.

Neste contexto, a porosidade do cenário de comunicação e os riscos associados à propagação de conteúdos descontextualizados são questionamentos que nos levam a assumir uma maior responsabilidade pelas mídias que escolhemos circular, porque ao assumir mais responsabilidades, evitamos propagar informações sem antes examinar atentamente. A responsabilidade também é uma maneira de contestamos boatos, impedindo que desinformações polêmicas ou perturbadoras possam ser encontradas em contextos inadequados. 


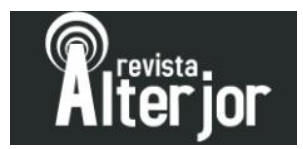

\section{Procedimentos Metodológicos}

A finalidade metodológica aplicada no presente estudo é a pesquisa descritiva, que tem o objetivo de descrever características de um fenômeno entre variáveis, além de relatar e comparar questões ao entorno do objeto. Sobre a pesquisa descritiva "são incluídas neste grupo as pesquisas que têm por objetivo levantar as opiniões, atitudes e crenças de uma população" (GIL, 2008, p. 28).

O estudo visa fazer uma investigação de forma ampla; por meio de uma pesquisa com foco em um estudo de caso, com objetivo de descrever um fenômeno atual dentro do contexto das notícias falsas e de sua propagação. Utilizamos como procedimentos metodológicos: a observação de como opera o programa Fato ou Fake, do G1, de julho de 2018 a agosto de 2020, a forma como se propagada a informação pela criação, produção e distribuição nas redes sociais online, e também nas categorias de análise agente, mensagem e intérprete.

O G1 é um portal de notícias do Grupo Globo, que está no ar desde 2006, compartilhando produções jornalísticas de diferentes empresas do grupo, como GloboNews, CBN, Extra, Valor Econômico, Época, Globo Rural, entre outros. Para Marinho, Marinho, Marinho (2011), há um tempo o jornalismo poderia ser facilmente classificado como a busca pela verdade dos fatos. No entanto, os autores defendem a necessidade de simplificar essa classificação, uma vez que o jornalismo passou a ser vítima de mal-entendidos, e que em certa medida como ferramenta de busca da verdade se tornou uma utopia, porque o conceito de verdade é subjetivo.

Em uma discussão filosófica, a verdade pode ser inesgotável e inalcançável, apesar de existir. Por essas questões, os autores definem o jornalismo como o "conjunto de atividades que, seguindo certas regras e princípios, produz um primeiro conhecimento sobre fatos e pessoas" (MARINHO, MARINHO, MARINHO, 2011, p. 3). Os autores afirmam que a Era Digital é bem-vinda, principalmente por permitir que os indivíduos se expressem livremente, seja de forma isolada, seja em grupo.

Com a consolidação da Era Digital, em que o indivíduo isolado tem facilmente acesso a uma audiência potencialmente ampla para divulgar o que quer que seja, nota-se certa confusão entre o que é ou 
não jornalismo, quem é ou não jornalista, como se deve ou não proceder quando se tem em mente produzir informação de qualidade. (MARINHO, MARINHO, MARINHO, 2011, p.1)

Paralelo à livre expressão, a Era Digital reforça a importância de as empresas que fazem jornalismo se expressarem formalmente acerca dos respectivos princípios que as norteiam. Ao reforçar seus princípios, as empresas se diferenciam e facilitam o julgamento do público sobre a atuação dos veículos de notícia, permitindo que o interlocutor defina, a partir dessa transparência, se os princípios da marca são condizentes com suas crenças. Com base nessa necessidade, o Grupo Globo compartilha seus próprios princípios editoriais - que são a isenção, a correção e a agilidade. $\mathrm{O}$ princípio da isenção prega a necessidade de criar notícias jornalísticas que sejam imparciais e apuradas de diferentes ângulos, esforçando-se para estarem isentos de diferentes vieses, posicionando como um grupo laico, apartidário, que repudia diferentes formas de preconceito e independe de governos.

\section{Estudo de Caso: programa Fato ou Fake do G1}

Para reforçar os princípios do Grupo Globo e alertar os brasileiros sobre conteúdos duvidosos que circulam na internet, surgiu o programa "Fato ou Fake", , do G1, que está no ar desde julho de 2018. O programa identifica notícias que circulam em redes sociais online e aplicativos de mensagens, como WhatsApp, e investiga a veracidade da informação. Os jornalistas do grupo monitoram os canais de comunicação diariamente a fim de conferir esse tipo de notícia e, além disso, também conta com a contribuição dos leitores para sugerirem checagens.

Ao identificar uma notícia potencialmente falsa, o jornalista inicia $o$ procedimento investigatório para esclarecer a veracidade da informação. Como metodologia, o jornalista verifica a fonte que deu início a notícia, avalia se está fora de contexto ou se é uma notícia antiga, e também analisa se as imagens apresentadas

\footnotetext{
${ }^{3}$ Disponível em: https:/g1.globo.com/fato-ou-fake/noticia/2018/07/30/g1-lanca-fato-ou-fake-novoservico-de-checagem-de-conteudos-suspeitos.ghtml — Acesso em 01/08/2020
} 


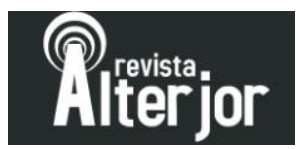

correspondem a narrativa.

$\mathrm{Na}$ etapa seguinte, a apuração manifesta fontes oficiais, testemunhas e especialistas que podem ajudar a esclarecer a mensagem. Concluída a apuração, o esclarecimento da notícia é publicado seguindo três princípios: transparência de fontes, que evidencia ao leitor o caminho de apuração em que o jornalista percorreu; transparência de metodologia, que destaca como ocorreu a apuração e o motivo que a classificou como fato ou fake; e a transparência de correções, que evidenciará eventuais modificações que comprometeram a publicação original.

Com a pandemia do coronavirus, novas notícias com potencial de desinformação circularam na internet acerca da temática ${ }^{4}$. Conforme apontado por Wardle e Derakhshan "informações médicas incorretas sempre representaram uma ameaça mundial à saúde" (2017, p.10). Mantendo os princípios do Grupo Globo e preservando o objetivo inicial do programa "Fato ou Fake", o G1 criou uma coluna exclusiva para tratar de desinformações relacionadas ao coronavírus. Ao esclarecer essas notícias e compartilhá-las com a comunidade, o programa busca combater desinformações que podem impactar diretamente na saúde da audiência. Entre as desinformações esclarecidas, de março a agosto de 2020, pelo programa "Fato ou Fake" conseguimos encontrar, por exemplo:

- É \#FAKE que máscaras de tecido sejam ineficazes contra o coronavírus e que apenas trajes cobrindo o corpo todo protejam da Covid- $19^{5}$

- É \#FAKE que produto veterinário creolina cure a Covid- $19^{6}$

- É \#FAKE que beber vodca ou uísque mate o coronavírus na garganta ${ }^{7}$

Uma das desinformações que mais repercutiu foi a de que a hidroxicloroquina -

\footnotetext{
${ }^{4}$ Disponível em: https://g1.globo.com/fato-ou-fake/coronavirus/ — acesso em 01/08/2020

${ }^{5}$ Disponível em: https://g1.globo.com/fato-ou-fake/coronavirus/noticia/2020/07/27/e-fake-que-mascarasde-tecido-sejam-ineficazes-contra-o-coronavirus-e-que-apenas-trajes-cobrindo-o-corpo-todo-protejam-dacovid-19.ghtml - Acesso em 01/08/2020

${ }^{6}$ Disponível em: https://g1.globo.com/fato-ou-fake/coronavirus/noticia/2020/07/17/e-fake-que-produtoveterinario-creolina-cure-covid-19.ghtml - Acesso em 01/08/2020

${ }^{7}$ Disponível em: https://g1.globo.com/fato-ou-fake/noticia/2020/07/10/e-fake-que-beber-vodca-ouuisque-mate-o-coronavirus-na-garganta.ghtml — Acesso em 01/08/2020
} 


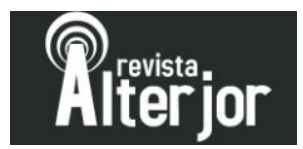

medicamento utilizado no combate à malária - é efetivo no combate ao coronavírus. Outras desinformações a respeito dessa mesma temática também se tornaram pauta de investigação do programa "Fato ou Fake", como a notícia de que médicos que não prescrevessem o uso da hidroxicloroquina a pedido do paciente em casos de coronavírus teriam o CRM $\operatorname{cassado}^{8}$ e também a notícia de que o medicamento era distribuído gratuitamente por toda Europa para tratar a doença'.

A Food and Drug Administration (FDA) ${ }^{10}$ — agência federal do Departamento de Saúde e Serviços Humanos dos Estados Unidos - rastreia problemas de segurança com medicamentos e direcionou esforços para entender o impacto do uso da hidroxicloroquina no combate ao coronavírus. Além de não comprovar cientificamente a eficácia da medicação no combate à doença, foi mapeado pela FDA casos de avarias cardíacas graves e mortes em pacientes com o vírus que receberam a medicação. Também foram mapeados distúrbios no sangue e no sistema linfático, lesões nos rins e insuficiência hepática.

O "Fato ou Fake" esclareceu que não há evidências científicas da eficácia da hidroxicloroquina no combate ao Coronavírus ${ }^{11}$. De acordo com a reportagem, "a Organização Mundial da Saúde diz que a cloroquina pode causar efeitos colaterais e não tem eficácia comprovada no tratamento da Covid-19" (G1, 2020). Ainda assim, essa desinformação ganhou grandes proporções e foi compartilhada por pessoas que possuem um grande alcance. Exemplo observado com o presidente Jair Messias Bolsonaro, que publicou um vídeo em sua rede social $^{12}$ afirmando estar com o vírus e utilizando o medicamento sem comprovação científica. No vídeo, o presidente afirma confiar na eficácia da medicação para o combate ao coronavírus e incentiva as pessoas a utilizarem.

\footnotetext{
${ }^{8}$ Disponível em: https://g1.globo.com/fato-ou-fake/noticia/2020/07/17/e-fake-que-pode-ter-o-crmcassado-o-medico-que-nao-prescrever-hidroxicloroquina-a-pedido-do-paciente-em-casos-de-covid.ghtml - Acesso em 01/08/2020

${ }^{9}$ Disponível em: https://g1.globo.com/fato-ou-fake/coronavirus/noticia/2020/06/25/e-fake-quecloroquina-seja-distribuida-gratuitamente-por-toda-a-europa-para-tratar-a-covid-19.ghtml — Acesso em $01 / 08 / 2020$

${ }^{10}$ Disponível em: https://www.fda.gov/drugs/drug-safety-and-availability/fda-cautions-against-usehydroxychloroquine-or-chloroquine-covid-19-outside-hospital-setting-or - Acesso em 01/08/2020

${ }^{11}$ Disponível em: https://g1.globo.com/fato-ou-fake/coronavirus/noticia/2020/05/21/e-fake-que-pesquisacom-6-mil-medicos-indique-a-hidroxicloroquina-como-o-tratamento-mais-eficaz-contra-ocoronavirus.ghtml - Acesso em 01/08/2020

${ }^{12}$ Disponível em: https://www.facebook.com/jairmessias.bolsonaro/videos/723015191608243/ — Acesso em $01 / 08 / 2020$
} 


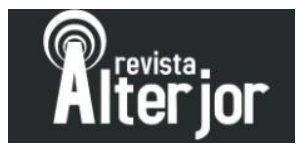

A inconsistência dos estudos feitos pela FDA (2020) sobre a eficácia da hidroxicloroquina no combate ao coronavírus levou o órgão a revogar o seu uso no combate à doença. Além disso, em reportagem do programa "Fato ou Fake", foi esclarecido que a Organização Mundial da Saúde não recomenda o uso da medicação. O programa direcionou esforços para esclarecer desinformações relacionadas ao assunto, uma vez que esse tipo de notícia foi livremente compartilhado nos canais de comunicação.

Nesse cenário, o programa "Fato ou Fake" investiga e esclarece essas e outras desinformações no objetivo de informar e educar a comunidade sobre os potenciais prejuízos que uma desinformação pode trazer, além de orientar os usuários a sempre questionarem uma notícia antes de comporem seu ciclo de propagação. Neste caso, observa-se que o agente é a própria população que acredita na informação com base no que o programa divulga. Tal contexto é identificado pela mensagem compartilhada. Destaca-se que o intérprete mobiliza a rede social na medida em que sua crença é uma confirmação de que faz sentido aquela informação. Portanto, o programa legitima a mensagem. Ainda que o Grupo Globo não tenha uma obrigatoriedade em combater notícias falsas, a instituição executa a tarefa de conscientização do público a partir de informações legítimas, uma vez que isso condiz com o princípio de isenção adotado pela marca.

As proporções que determinadas desinformações ganham dentro da cadeia de compartilhamento são, por vezes, imensuráveis — o que impossibilita a identificação da raiz da notícia. A criação de notícias falsas é difícil de se comprovar, no entanto, sempre há indícios. As evidências são na forma intensa de distribuição, caracterizada pelo ato de compartilhar. O Grupo Globo tem evidenciado a necessidade de investigar a fonte das notícias e buscar esclarecimento com especialistas antes de propagar a mensagem, sempre adotando chamadas que orientam o interlocutor a se responsabilizar pela mensagem que compartilha. Contudo, nota-se que além de combater a desinformação, o desafio se estende para a conscientização da população.

Revista ALTERJOR

Grupo de Estudos Alterjor: Jornalismo Popular e Alternativo (ECA-USP)

Ano 10 Volume Ol Edição 23 Janeiro-Junho de 2021

Avenida Professor Lúcio Martins Rodrig̉ues, 443, Cidade Universitária, São Paulo, CEP: 05508-020 


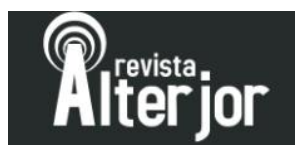

\section{Considerações Finais}

Entendemos que conceituar notícia como uma representação da verdade é uma maneira ainda contextualizada, uma vez que a verdade é subjetiva e depende da crença do indivíduo. Entretanto, o oposto de uma notícia verdadeira é classificado como uma desinformação, já que notícias falsas poluem e desordenam informações, que são elementos que, se bem construídos, são essenciais para o bem-estar social. A propagação de desinformações conta com diferentes motivações e a finalidade do indivíduo potencializador do conteúdo falso ou descontextualizado não é, necessariamente, maldosa. Ainda que a finalidade não seja duvidosa, a desinformação tem o potencial de causar prejuízos à saúde pública e ao bem-estar social.

As redes sociais online construíram um canal democrático de compartilhamento de notícias, que foram somadas à desordem das informações. Como resultado, todo indivíduo que tem acesso à internet se tornou um produtor de conteúdo (fases de produção e distribuição) com potencial de influenciar sua rede. Entretanto, produtores e propagadores de conteúdo não contam com consequências para as desinformações circuladas. Enquanto não houver legislação que puna produtores de conteúdos duvidosos, é uma responsabilidade da sociedade checar as procedências das notícias compartilhadas.

O Grupo Globo é um exemplo de um emissor de notícias que busca, a partir do programa "Fato ou Fake", do G1, praticar seus princípios de marca e prestar um serviço informacional à sociedade. Ainda que porta-vozes importantes sejam responsáveis pela propagação de desinformações, o programa "Fato ou Fake" preza pelo princípio da isenção e esclarece todas as desinformações com especialistas e investigação de fonte. O programa orienta os interlocutores a questionarem as notícias antes de se renderem ao ciclo de propagação da desinformação. Por fim, podemos inferir que a responsabilidade em combater a desinformação é coletiva, uma vez que cada intérprete deve considerar, como critério para propagação de uma mensagem, a veracidade e a potencial influência que pode ser gerada pelo agente em sua rede de contatos. 


\section{Referências}

ALSINA, Miquel Rodrigo. La construcción de la noticia. Barcelona: Ediciones Paidós, 1993.

BOLSONARO, Jair Messias (Jair Messias Bolsonaro). Eu tomei a Hidroxicloroquina e estou me sentindo muito bem. Uma boa tarde a todos. Brasília, 7 de julho de 2020. Facebook: jairmessias.bolsonaro. Disponível em:

<https://www.facebook.com/jairmessias.bolsonaro/videos/723015191608243/> Acesso em: 01 de agosto de 2020.

É \#FAKE que beber vodca ou uísque mate o coronavírus na garganta. G1, Rio de Janeiro, 10 de julho de 2020. Disponível em: <https://g1.globo.com/fato-ou-fake/noticia/2020/07/10/e-fakeque-beber-vodca-ou-uisque-mate-o-coronavirus-na-garganta.ghtml >. Acesso em: 01 de agosto de 2020.

É \#FAKE que cloroquina seja distribuída gratuitamente por toda a Europa para tratar a Covid19. G1, Rio de Janeiro, 25 de junho de 2020. Disponível em: <https://g1.globo.com/fato-oufake/coronavirus/noticia/2020/06/25/e-fake-que-cloroquina-seja-distribuida-gratuitamente-portoda-a-europa-para-tratar-a-covid-19.ghtml>. Acesso em: 01 de agosto de 2020.

É \#FAKE que máscaras de tecido sejam ineficazes contra o coronavírus e que apenas trajes cobrindo o corpo todo protejam da Covid-19. G1, Rio de Janeiro, 27 de julho de 2020.

Disponível em: <https://g1.globo.com/fato-ou-fake/coronavirus/noticia/2020/07/27/e-fake-quemascaras-de-tecido-sejam-ineficazes-contra-o-coronavirus-e-que-apenas-trajes-cobrindo-ocorpo-todo-protejam-da-covid-19.ghtml>. Acesso em: 01 de agosto de 2020.

G1 lança Fato ou Fake, novo serviço de checagem de conteúdos suspeitos. G1, Rio de Janeiro, 30 de julho de 2018. Disponível em: <https://g1.globo.com/fato-ou-fake/noticia/2018/07/30/g1lanca-fato-ou-fake-novo-servico-de-checagem-de-conteudos-suspeitos.ghtml >. Acesso em: 01 de agosto de 2020.

É \#FAKE que pode ter o CRM cassado o médico que não prescrever hidroxicloroquina a pedido do paciente em casos de Covid. G1, Rio de Janeiro, 17 de julho de 2020. Disponível em: <https://g1.globo.com/fato-ou-fake/noticia/2020/07/17/e-fake-que-pode-ter-o-crm-cassado-omedico-que-nao-prescrever-hidroxicloroquina-a-pedido-do-paciente-em-casos-de-covid.ghtml>. Acesso em: 01 de agosto de 2020.

É \#FAKE que pesquisa recente indique a hidroxicloroquina como o tratamento mais eficaz contra o coronavírus. G1, Rio de Janeiro, 21 de maio de 2020. Disponível em: <https://g1.globo.com/fato-ou-fake/coronavirus/noticia/2020/05/21/e-fake-que-pesquisa-com-6mil-medicos-indique-a-hidroxicloroquina-como-o-tratamento-mais-eficaz-contra-ocoronavirus.ghtml>. Acesso em: 01 de agosto de 2020.

É \#FAKE que produto veterinário creolina cure a Covid-19. G1, Rio de Janeiro, 17 de julho de 2020. Disponível em: <https://g1.globo.com/fato-ou-fake/coronavirus/noticia/2020/07/17/efake-que-produto-veterinario-creolina-cure-covid-19.ghtml >. Acesso em: 01 de agosto de 2020.

Revista ALTERJOR

Grupo de Estudos Alterjor:Jornalismo Popular e Alternativo (ECA-USP)

Ano 10 Volume Ol Edição 23 Janeiro-Junho de 2021

Avenida Professor Lúcio Martins Rodrig̉ues, 443, Cidade Universitária, São Paulo, CEP: 05508-020 


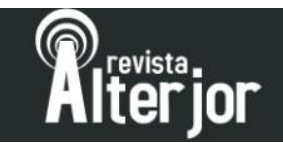

FDA cautions against use of hydroxychloroquine or chloroquine for COVID-19 outside of the hospital setting or a clinical trial due to risk of heart rhythm problems. U. S. Food and drug administration, Silver Spring, MD, 15 de junho de 2020. Disponível em:

$<$ https://www.fda.gov/drugs/drug-safety-and-availability/fda-cautions-against-usehydroxychloroquine-or-chloroquine-covid-19-outside-hospital-setting-or>Acesso em 1 de agosto de 2020.

GIL, Antônio Carlos. Métodos e técnicas de pesquisa social. São Paulo: Editora Atlas S.A., 2008.

JENKINS, Henry. GREEN, Joshua. FORD, Sam. Cultura da conexão: criando valor e significado por meio da mídia propagável. São Paulo: Editora Aleph, 2014.

MARINHO, Roberto Irineu. MARINHO, João Roberto. MARINHO, José Roberto. Princípios Editoriais do Grupo Globo. Rio de Janeiro: Grupo Globo, 2011. Disponível em <http://g1.globo.com/principios-editoriais-do-grupo-globo.html\#principios-editoriais> Acesso em: dia 1 de agosto de 2020.

WARDLE, Caire. DERAKHSHAN, Hossein. Information disorder: Toward an interdisciplinary framework for research and policy making. Strasbourg: Council of Europe. 2017. 